\title{
Landslide disaster mitigation plan in Karang Tengah Village, Bantul district, Yogyakarta
}

\author{
Mochamad Teguh ${ }^{1}$, Sri Aminatun ${ }^{1, *)}$, and Wisnu Erlangga ${ }^{1}$ \\ ${ }^{1}$ Department of Civil Engineering and Disaster Risk Management, Islamic University of Indonesia, Indonesia
}

\begin{abstract}
Karang Tengah Village is one of the villages that are vulnerable to landslides that located on the topography of the ridge to the hills in the eastern region of Bantul Regency. Based on the map of landslides incident from the Regional Disaster Management Agency in 2011, Karang Tengah Village has steep slopes, so it has a high potential for landslides. One way to mitigate landslide disaster is to assess and analyze the risk of landslide disaster in detail. This study aims to identify the homes of residents who are in the landslide threat zone, be it a high or medium threat zone. The method used in this research is descriptive method with qualitative approach combined with a quantitative method used to give a clear picture of the number of houses in each zonation. Sources of data used are primary and secondary data sources through interviews and documentation. The results of this study indicate that 1) the number of households in the high-risk zone is 63 houses, in the yellow risk zone is 59 houses. 2) The village of Karang Tengah has a high threat, medium to high vulnerability, and medium capacity, which means having a medium to high risk. 3) Recommended infrastructure.
\end{abstract}

\section{Introduction}

Bantul Regency is located in a transitional region, which is the plain that originates from the volcanic activity and river sediment/fluvial-Vulcan. The form of fluvial land is caused by the activity of river flow, such as erosion and sediment transportation. It forms a stretch of alluvial plains and other formations with horizontal structures composed of a sedimentary material slope.

The area of Bantul Regency has a topography as a lowland of $40 \%$ and less fertile hilly regions of $60 \%$. The western part is a less sloping area and hills stretching from north to south and covers an area of $89.86 \mathrm{~km} 2(17.73 \%$ of the total area). The central part is a flat and sloping area, which is a fertile agricultural area of $210.94 \mathrm{~km} 2$ (41, $62 \%$ ). The eastern part is slanted, sloping and steep areas whose condition is still better than the western part, covering an area of $206.05 \mathrm{~km} 2(40.65 \%)$ while the southern part is part of the central part of the region with its natural state, sandy ones.

Based on the data of landslide events that occurred in the Bantul Regency, the topographic map is presented in Fig. 1. The landslide occurrence map is categorized into three different colors in marking for three levels of landslide frequency. They are concentrated as red areas having most often landslides occurred, and pink for rather frequent landslides. More detailed researches are needed regarding the disaster risk assessment due to the results of the landslide studies are still in the global form [1-3].

The study of disaster risk analysis by conducting disaster risk mapping does not yet have a standardized standard in preparing for disaster risk maps so that each institution has a different method. Likewise, with the assessment of landslide risk analysis is carried out in the Terong village.

Karang Tengah Village is one of the villages in Imogiri Subdistrict, Bantul Regency, in the province of the Special Region of Yogyakarta. It is located in a hilly area with steep slope levels so that the village is a landslide-prone area, and every rainy season, the region experiences a landslide. The landslide impact reduction is not always carried out by improving the condition of the building structure because each part has different building needs [4]. A strategy of disaster risk reduction is created by a safe condition, which is intensified the movement of disaster risk reduction [5]. In order to reduce the landslide risk in Bantul district, a study on the landslide risk analysis is an essential in accordance with the Disaster Management Law No.24 of 2007 [6] and the United Nation-International Strategy for Disaster Reduction (UN-ISDR) [7] and in order to implement the results of the Disaster Risk Reduction conference in the form of the Sendai Framework for Disaster Risk Reduction (20152030) [8].

The mapping of landslide risk used in this study has specific criteria and parameters. Although they may not be very different from other institutions, they still have the same principle of the study of elemental maps. Previous research on the landslide risk analysis carried out by the World Bank in collaboration with the Bantul Regency is extended in this research [2].

The study aimed to find out the number of houses in each disaster risk zone (red, yellow, green) and define the value of each parameter as a determinant of the risk of

\footnotetext{
* Corresponding author: sri.aminatun@
} 
landslides in Karang Tengah village, Imogiri District as well as the determination of the landslide mitigation program in each of these risk zones.

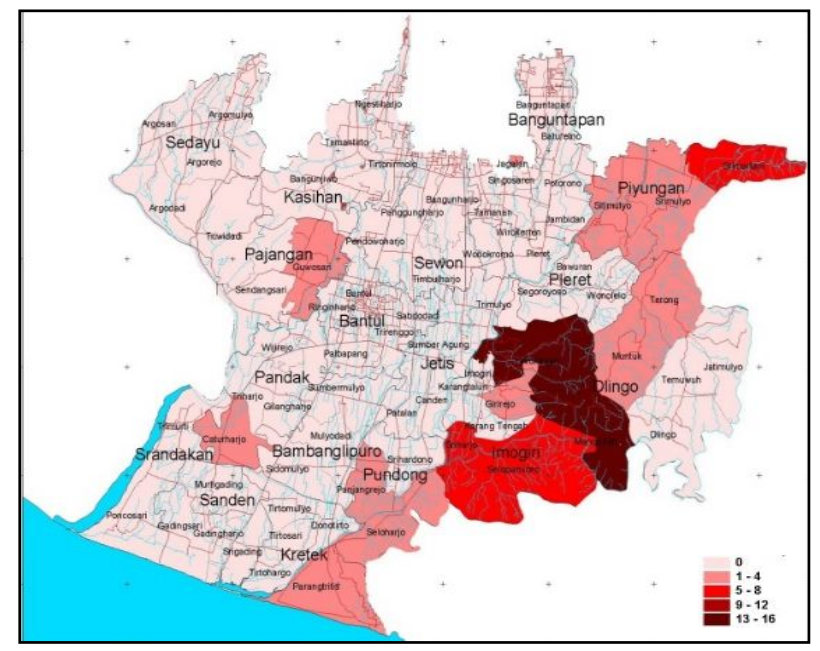

Fig. 1. Topographic Map of Bantul Regency

\section{Reserarch Meethods}

Significant data was collected by making direct observations (interview and documentation) and taking measurements. Process of interviews and FGDs (Focus Group Discussion) was well done by face to face dialogue or focus group discussions with key informants consisting of residents, community leaders, women, and youth leaders, related officials at the village, sub-district and district levels. While in the documentation process, the secondary data that were collected in the form of documents needed for study material, including study materials that had been prepared previously. The next process was to conduct an assessment or study directly in the study area by filling in the form that was developed with the parameters specified. The evaluation of measurements was based on the score of Indonesian regulations [9-11]. The ratings 1 to 3 show the level of impacts where 1 is low, 2 is medium, and 3 is high, and the weight value is based on how much a parameter influences the threat of a disaster.

The data obtained is based on each parameter inventoried and classified, then determined the level and magnitude of the indicators achieved. The scale and magnitude of the grouped indicators are then tabulated and identified the vulnerability of each location point based on the location points that have been labelled. Furthermore, analyses of threat, vulnerability, and community capacity are carried out. Based on the vulnerability analysis, the risk level of landslide vulnerability can be determined from the point position that has been studied. A mapping process based on the analysis is then carried out, supported by Geological maps, slope maps, rainfall maps, and land use maps. With the mapping process carried out with several support maps, then the maps are overlaid using the Spatial Geographical Information System with the ArcGIS program. The generated map presents the landslide threat and risk maps.
Maps that have been made are then carried out socialization to the base/village with community representatives to validate the results of maps that have been made through FGD (Focus Group Discussion). The effects of the initial socialization will be an evaluation in improving the final map making. After the final mapmaking process was completed, then it was re-socialized through a workshop attended by the Bantul Regional Government, instruments, and representatives of the Study village community, community leaders, and related stakeholders.

\subsection{Disaster Risk Analysis}

Landslide risk assessment is based on three parameters according to the formula agreed upon in the Hyogo Framework for Action, namely:

$$
R=\frac{H}{C} \times V
$$

where $R$ is the risk; $H$ is a hazard; $C$ is capacity, and $V$ is vulnerability.

In the study of landslide risk analysis, this is not only based on scientific considerations but also takes into account participatory patterns that involve the community as a subject and object of study and stakeholders at the village and district level. It is intended that in carrying out disaster risk assessments not only are partial but also carried out holistically as a form of joint learning.

\subsection{Weighting of Threat Parameters}

The weighting of threat parameters is carried out based Indonesia Regulation concerning Risk Assessment [911], as presented in Table 1.

Table 1. Weighting parameters for landslide threats

\begin{tabular}{|c|c|c|c|c|}
\hline \multirow{2}{*}{ No } & \multirow{2}{*}{ Parameter } & \multirow{2}{*}{ Weight } & \multicolumn{2}{|c|}{ Score } \\
\hline & & & Minimum & Maximum \\
\hline 1 & $\begin{array}{l}\text { Soil texture } \\
\text { class }\end{array}$ & 1 & 1 & 3 \\
\hline 2 & $\begin{array}{l}\text { Soil solum } \\
\text { thickness }\end{array}$ & 1 & 1 & 3 \\
\hline 3 & $\begin{array}{l}\text { Rock } \\
\text { weathering } \\
\text { level }\end{array}$ & 1 & 1 & 3 \\
\hline 4 & Slope angle & 5 & 5 & 15 \\
\hline 5 & $\begin{array}{l}\text { Types of } \\
\text { morphology }\end{array}$ & 3 & 3 & 9 \\
\hline 6 & $\begin{array}{l}\text { History of } \\
\text { landslides }\end{array}$ & 1 & 1 & 3 \\
\hline 7 & $\begin{array}{l}\text { Vegetative } \\
\text { density }\end{array}$ & 1 & 1 & 3 \\
\hline 8 & Land use & 1 & 1 & 3 \\
\hline 9 & Rainfall data & 1 & 1 & 3 \\
\hline & Total & & 15 & 45 \\
\hline
\end{tabular}

The slope angle and type of morphology have a significant weight because these parameters have an enormous influence on the threat of landslides. The assessment of the weighting parameters of the effect of landslides is carried out with a Weighted Method by calculating the amount of maximum weighting value 
reduced by the number of minimum weighting values. This reduction result is divided by the desired number of classes which, in this case, divide it into three categories, then the interval of hazard criteria score is generated in Eq. 2 as follows:

$$
\text { Interval }=\frac{\text { Max Score }- \text { Min Score }}{3}=\frac{45-15}{3}=10
$$

Based on the calculated scores, threat zone intervals can be categorized as presented in Table 2 .

Table 2. Threat weighting intervals

\begin{tabular}{|c|c|c|}
\hline Interval Score & Criteria & Class (Zone) \\
\hline $15-24$ & Low & Green \\
\hline $25-34$ & Medium & Yellow \\
\hline $35-45$ & High & Red \\
\hline
\end{tabular}

\subsection{Disaster Risk Map}

The preparation of this landslide risk mapping uses three scoring classes and weighting methods for each parameter. Weighting the components of landslide risk map compilation is based on Perka No. 2 of 2012 concerning the General Guidelines for Disaster Risk Assessment [11].

\subsection{Weighting of Vulnerability Parameters}

Vulnerability is the condition or biological, economic, social, cultural, political, cultural, and technological characteristics of a society in a region for a period that reduces the community to prevent, reduce, achieve readiness and respond to the effects of specific hazards.

Table 3. The weighting of landslide vulnerability parameters

\begin{tabular}{|c|l|c|c|c|}
\hline \multirow{2}{*}{ No } & \multicolumn{1}{|c|}{ Rated Element } & \multirow{2}{*}{ Weight } & \multicolumn{2}{|c|}{ Score } \\
\cline { 4 - 5 } 1. & $\begin{array}{l}\text { Number of heads of } \\
\text { families in one house }\end{array}$ & 1 & 1 & 3 \\
\hline 2. & $\begin{array}{l}\text { Number of family } \\
\text { members in one } \\
\text { house }\end{array}$ & 1 & 1 & 3 \\
\hline 3. & $\begin{array}{l}\text { Status of home } \\
\text { ownership }\end{array}$ & 1 & 1 & 2 \\
\hline 4. & $\begin{array}{l}\text { Land ownership } \\
\text { status }\end{array}$ & 1 & 1 & 2 \\
\hline 5. & Land area & 1 & 1 & 3 \\
\hline 6. & Building type & 3 & 3 & 9 \\
\hline 7. & Other land uses & 1 & 1 & 3 \\
\hline & \multicolumn{1}{|c|}{ Total } & & 9 & 25 \\
\hline
\end{tabular}

Components of vulnerability used in this method include physical, demographic, economic, and environmental elements. The weighting of vulnerability parameters based on regulations [9-11] is presented in Table 3. In the vulnerability parameters, the type of building is very influential on susceptibility to landslides, so it is given a weight value of 3 . By using a Weighted Method, the risk criteria score interval is determined in the following calculations (Eq.3):

$$
\text { Interval }=\frac{\text { Max Score }- \text { Min Score }}{3}=\frac{25-9}{3}=5.33 \approx 5
$$

The results of the vulnerability weighting interval are depicted in Table 4.

Table 4. Vulnerability weighting intervals

\begin{tabular}{|c|c|c|}
\hline Inteval Score & Criteria & Class (Zone) \\
\hline $9-14$ & Low & Green \\
\hline $15-19$ & Medium & Yellow \\
\hline $20-21$ & High & Red \\
\hline
\end{tabular}

\subsection{Capacity Weighting Parameter}

Capacity or capability is a resource, means, and strength that is owned by the community that allows the community to maintain and prepare themselves, prevent, respond, reduce and quickly recover from the consequences of disasters. Community capacity can be in the form of physical and non-physical (social) components. The physical and non-physical (social) components are measured based on the village area because the smallest spatial administrative data is the village. Weighting the capacity parameters is presented in Table 5 [9-11].

\begin{tabular}{|c|c|c|c|c|}
\hline \multirow{2}{*}{ No } & \multirow{2}{*}{ Rated Element } & \multirow{2}{*}{ Weight } & \multicolumn{2}{|c|}{ Score } \\
\hline & & & Min & Max \\
\hline 1. & $\begin{array}{l}\text { Number of hospitals, } \\
\text { puskesmas, polindes }\end{array}$ & 1 & 1 & 3 \\
\hline 2. & Number of schools & 1 & 1 & 3 \\
\hline 3. & $\begin{array}{l}\text { Number of medical } \\
\text { personnel }\end{array}$ & 1 & 1 & 3 \\
\hline 4. & Institution PRB & 1 & 1 & 3 \\
\hline 5. & $\begin{array}{l}\text { Markings/signs of } \\
\text { evacuation route }\end{array}$ & 1 & 1 & 3 \\
\hline 6. & Early warning System & 1 & 1 & 3 \\
\hline \multicolumn{3}{|c|}{ Total } & 6 & 18 \\
\hline
\end{tabular}

Table 5. The weighting of landslide capacity parameters

By using the Weighted Method, the risk criteria score interval is defined using Eq. 4.

$$
\text { Interval }=\frac{\text { Max Score }- \text { Min Score }}{3}=\frac{18-6}{3}=4
$$

The results of the capacity weighting interval are shown in Table 6.

Table 6. Capacity Weighting Intervals

\begin{tabular}{|c|c|c|}
\hline Inteval Score & Criteria & Class (Zone) \\
\hline $6-10$ & Low & Green \\
\hline $11-14$ & Medium & Yellow \\
\hline $15-18$ & High & Red \\
\hline
\end{tabular}

\subsection{Disaster Risk Weighting}

The weighting of disaster risk for disaster risk assessment is presented in Table 7. The data on disaster risk weighting is obtained from the maximum score and minimum score from the hazard, vulnerability, and capacity data in the previous section. In contrast, the multiplier of each 
parameter is based on how much influence these parameters on landslides risk.

Table 7. The weighting of landslide disaster risks

\begin{tabular}{|l|c|c|c|c|c|}
\hline \multirow{2}{*}{$\begin{array}{c}\text { Rated } \\
\text { Element }\end{array}$} & \multicolumn{2}{|c|}{ Score } & \multirow{2}{*}{ Multiplier } & \multicolumn{2}{c|}{ Score } \\
\cline { 2 - 3 } \cline { 5 - 6 } & Min & Max & & Min & Max \\
\hline Hazard & 15 & 45 & 0.5 & 7.5 & 22.5 \\
\hline Vulnerabilty & 9 & 25 & 0.3 & 2.7 & 7.5 \\
\hline Capacity & 6 & 15 & 0.2 & 1.2 & 3.6 \\
\hline \multicolumn{3}{|c|}{ Total } & 1 & 11.4 & 33.6 \\
\hline
\end{tabular}

Similarly using the Weighted Method, the risk criteria score interval is computed referring to Eq. 5 as follows:

$$
\text { Interval }=\frac{\text { Max Score }- \text { Min Score }}{3}=\frac{33.6-11.4}{3}=7.4
$$

and the risk criteria score interval is determined in Table 8.

Table 8. Disaster risk weighting intervals

\begin{tabular}{|c|c|c|}
\hline Inteval Score & Criteria & Class (Zone) \\
\hline $26.3-33.6$ & Low & Green \\
\hline $18.9-26.2$ & Medium & Yellow \\
\hline $11.4-18.8$ & High & Red \\
\hline
\end{tabular}

\subsection{Geographic Information System (GIS)}

Geographic Information System (GIS) consists of a set of components that cannot be separated from one another. These components are as follows:

1. brain ware (human),

2. data, in the form of analog maps, survey data, statistics, aerial photographs, previous GIS data, etc.,

3. hardware (computer hardware and supporting equipment and communication hardware), e.g., computer, scanner, digitizer,

4. software (software), for example, ArcGis, Map Info, Surfer, Autocad, etc.

The software used is ArcGis, Version 9.3, to calculate and evaluate the slope percentage, which units, classes, or types of each map are essential on the occurrence of ground movements. Besides, units and types of each map were critical (influential) on the occurrence of ground movements. According to the Decree of the Minister of Energy and Mineral Resources of Indonesia No.1452/K/10/MEM/2000 concerning Technical Guidelines for Mapping the Zone of Vulnerability of Land Movements, mapping of land vulnerability zones can be performed by direct mapping, indirect mapping, and combined methods.

In addition to using the GIS method, the approach is also a quantitative method (statistical method). This method is based on the calculation of ground motion density and the weight value of each unit and type on each parameter map.
Based on the computation, the density value of unit and type in each map parameter is a reflection of the extent of the ground motion occurrence in one group (unit, type) per area of the unit area, and parameter type.

\section{Results and Discussion}

\subsection{Threat Weighting (Hazard)}

After rating each indicator and parameters, then each of these parameters is weighted based on the magnitude of the influence of these parameters on the threat of landslides that occur. The weighting parameters of the threat of vulnerability of landslides in Karang Tengah Village, Bantul Regency are presented in Table 9.

Table 9. Results of landslide vulnerability threat assessment

\begin{tabular}{|c|l|c|c|c|}
\hline No & \multicolumn{1}{|c|}{ Parameter } & Weight & Score & Total \\
\hline 1 & Soil texture class & 1 & 3 & 3 \\
\hline 2 & Soil solum thickness & 1 & 2 & 2 \\
\hline 3 & Rock weathering level & 1 & 3 & 3 \\
\hline 4 & Slope angle & 5 & 3 & 15 \\
\hline 5 & Types of morphology & 3 & 3 & 9 \\
\hline 6 & History of landslides & 1 & 2 & 2 \\
\hline 7 & Vegetative density & 1 & 3 & 3 \\
\hline 8 & Land use & 1 & 3 & 3 \\
\hline 9 & Rainfall data Total & 1 & 2 & 2 \\
\hline \multicolumn{4}{|c|}{} & 42 \\
\hline
\end{tabular}

Note: soil solum is the upper part of the soil profile, the right seat of the soil-forming process, and is the principal habitat for soil organisms, which is influenced by plant roots.

Table 9 presents the assessment results of the landslide vulnerability threat giving the total score of 42 . Given this condition, it can be summarized that Karang Tengah Village has high threat criteria so that it is included in the red zone.

\subsection{Vulnerability}

The weighting of landslide vulnerability parameters shown in Table 10. From the total score computed, the value of vulnerability is 22 so that it can be categorized in the red zone, namely the criteria for high vulnerability.

Table 10. The weighting of landslide vulnerability parameters

\begin{tabular}{|c|c|c|c|c|}
\hline No & Rated Element & Weight & Score & Total \\
\hline 1 & $\begin{array}{l}\text { Number of heads of } \\
\text { families in one house }\end{array}$ & 1 & 2 & 2 \\
\hline 2 & $\begin{array}{l}\text { Number of family } \\
\text { members in one house }\end{array}$ & 1 & 3 & 3 \\
\hline 3 & $\begin{array}{l}\text { Status of home } \\
\text { ownership }\end{array}$ & 1 & 2 & 2 \\
\hline 4 & Land ownership status & 2 & 2 & 4 \\
\hline 5 & Land area & 1 & 1 & 2 \\
\hline 6 & Building type & 3 & 2 & 6 \\
\hline 7 & Other land uses & 1 & 3 & 3 \\
\hline \multicolumn{4}{|c|}{ Total } & 22 \\
\hline
\end{tabular}


Table 11. Results of the assessment of parameter of landslide capacity

\begin{tabular}{|c|l|c|c|c|}
\hline No & \multicolumn{1}{|c|}{ Rated Element } & Weight & Score & Total \\
\hline 1. & $\begin{array}{l}\text { Number of hospitals, } \\
\text { Puskesmas, polindes }\end{array}$ & 1 & 2 & 2 \\
\hline 2. & Number of schools & 1 & 2 & 2 \\
\hline 3. & $\begin{array}{l}\text { Number of medical } \\
\text { personnel }\end{array}$ & 1 & 2 & 2 \\
\hline 4. & Institutional PRB & 1 & 3 & 3 \\
\hline 5. & $\begin{array}{l}\text { Markings/signs of } \\
\text { evacuation route }\end{array}$ & 2 & 3 & 6 \\
\hline 6. & Early warning system & 1 & 3 & 3 \\
\hline \multicolumn{4}{|c|}{ Total } \\
\hline
\end{tabular}

\subsection{Capacity}

Results of the assessment of the parameter of landslide capacity have shown a shred of evidence that Karang Tengah Village has the criteria of moderate capacity with the yellow zone. The data shows the number of scores calculated is 17, as depicted in Table 11.

\subsection{Risk Analysis}

Landslide risk analysis is a combination of three main components, namely threats $(\mathrm{H})$, vulnerability $(\mathrm{V})$, and capacity (C). Each total weight of hazard, vulnerability, and capacity for this risk was presented in previous sections. The results of the hazard, vulnerability, capacity, and risk zones are completely tabulated in Table 12. The results of the mapping based on the landslide risk zone in Karang Tengah village, Imogiri, are pictured in Fig. 2.

Table 12. Classification of hazard (H), vulnerability (V), capacity $(\mathrm{C})$, and risk $(\mathrm{R})$ zones

\begin{tabular}{|c|c|c|c|c|c|}
\hline $\begin{array}{c}\text { Data on } \\
\text { Number of } \\
\text { Houses }\end{array}$ & \multicolumn{5}{|c|}{ Zone } \\
\cline { 2 - 6 } & Classified & $\mathrm{H}$ & $\mathrm{V}$ & $\mathrm{C}$ & $\mathrm{R}$ \\
\hline \multirow{4}{*}{ Karangrejek } & Red & 63 & 3 & 0 & 63 \\
\cline { 2 - 6 } & Yellow & 0 & 2 & 1 & 0 \\
\cline { 2 - 6 } & Green & - & - & 2 & - \\
\hline \multirow{3}{*}{ Mojolegi } & Red & 51 & 4 & 0 & 0 \\
\cline { 2 - 6 } & Yellow & 0 & 5 & 3 & 51 \\
\cline { 2 - 6 } & Green & - & - & 7 & - \\
\hline \multirow{3}{*}{$\begin{array}{c}\text { Pucung } \\
\text { Growong }\end{array}$} & Red & 1 & 1 & 0 & 0 \\
\cline { 2 - 6 } & Yellow & 7 & 0 & 0 & 8 \\
\cline { 2 - 6 } & Green & - & - & - & - \\
\hline
\end{tabular}

Based on Table 12 and Fig. 2, a huge number of residents live in the red zone and yellow zone, which are very prone to landslides.

Landslide risk maps can be used for disaster management. It represents threats that vary by area, which facilitates the process of selecting the areas that should be prioritized in the event of a landslide. In the application, the age or use of the map can be used immediately after the map is published until a new map update occurs when needed. The need for updating risk maps is usually based on significant environmental changes in the area or other factors that can affect disaster risk. In the manufacturing process, the risk map takes into account all aspects that can affect disaster risks such as threats, capacities, and vulnerabilities in the area under review. Therefore, the accuracy of the threat map is dependent on the actual situation in the area under investigation. Besides, knowledge of the different levels of risk makes it easy to mitigate what is appropriate for each area.

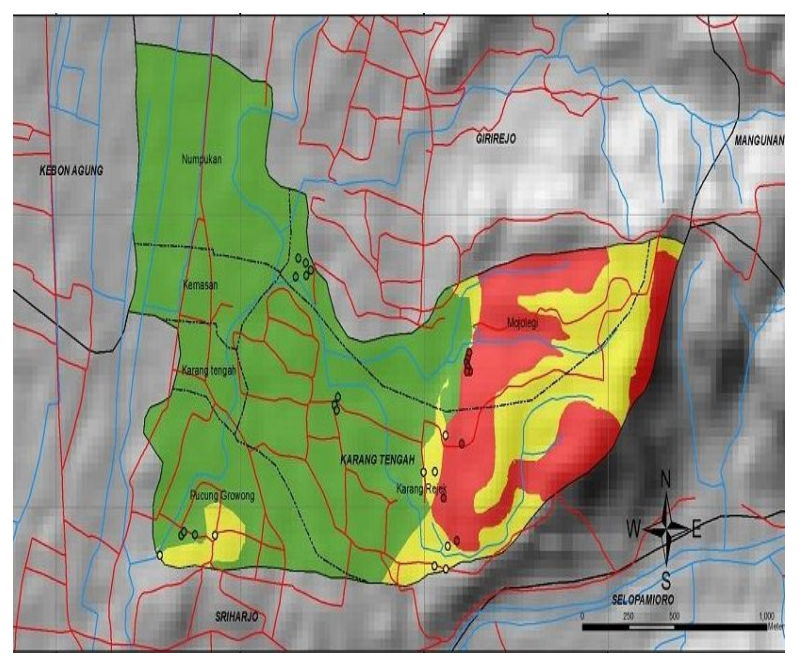

Fig 2. Landslide risk map of Karang Tengah Village, Imogiri, Bantul

\subsection{Development Program Recommendations}

The results of a landslide risk assessment at Karang Tengah village, cause an essential development related to infrastructure in the area based on the level of disaster risk, as follows:

1. High risk

In high-risk areas, disaster risk reduction is in the form of relocation, which is to move people from high-risk areas to safe places. The buildings in the location of relocation use the concept of earthquake-resistant structures. Road Evacuation has a minimum of 2 lanes so that four-wheeled vehicles can run in good traffic, drainage channels, and places of worship.

2. Medium risk

In risk areas, infrastructure is being built, which includes: ground retaining wall, drainage channels, and road evacuation.

\section{Conclusion}

The landslide disaster mitigation plan in Karang Tengah Village of Bantul District produces several essential points.

1. The number of houses in the risk red zone is 63 houses, and the yellow zone consists of 59 risk houses.

2. Karang Tengah village has moderate to high threat value, moderate to high vulnerability, and low to moderate capacity, so the risk value is moderate to high.

3. Disaster risk reduction in this area is necessary to increase the capacity to mitigate disasters in the form 
of physical or infrastructure and non-physical conditions, such as:

a. relocating people into a safe place and constructing earthquake-resistant houses are strongly recommended in the high-risk regions,

b. building retaining walls, drainage canals, and tree planting is the best choice in the moderate risk area.

\section{References}

1. D Haryanto, Landslide Risk Assessment in Semarang City, Central Java Province, Postgraduate Program at the Faculty of Engineering, Gadjah Mada University, Yogyakarta (2009)

2. S. Aminatun, Landslide Disaster Risk Analysis in Bantul Regency, Global Facility for Disaster Reduction and Recovery in collaboration with Bantul Regency, The World Bank (2013)

3. BAPPEDA DIY, Disaster Risk Mapping Method of the Special Province of Yogyakarta (2008)
4. B. K. Dahal and R. K. Dahal, Geoenvironmental Disasters. 4 (2017).

5. D A P Sari, S Innaqa and Safrila, IOP Conf. Series: Materials Science and Engineering 209 (2017).

6. Law of the Republic of Indonesia No.24 of 2007 concerning Disaster Management (2007)

7. United Nation-International Strategy for Disaster Reduction (UN-ISDR), Guide to Implementing the Sendai Framework (2007).

8. National Disaster Management Agency (BNPB), Sendai Framework for Disaster Risk Reduction (2015-2030) (2015).

9. Government Regulation No.21 of 2008, concerning the Implementation of Disaster Management (2008).

10. BNPB, Regulation of the Head of the National Disaster Management Agency of the Republic of Indonesia, No.4 of 2008 concerning Guidelines for Disaster Management Plans (2008).

11. BNPB, Regulation of the Head of the National Disaster Management Agency of the Republic of Indonesia, No.2 of 2012 concerning General Guidelines for Disaster Risk Assessment (2012). 